\title{
El principio de la mayoría en la Junta General de Accionistas y su aplicabilidad conforme al Código de Comercio Nicaragüense.
}

\author{
The principle of majority in the Gneral Shareholders' Meeting and its
} applicability according to Nicaraguan Commercial Code

\section{Dr. Cristian Alberto Robleto Arana*}

\section{Resumen}

El estudio del principio de la mayoría de la Junta General de Accionista nos permite realizar un análisis de fondo de las disposiciones contenidas en el Código de Comercio de Nicaragua y compararla con la doctrina contemporánea y la legislación extranjera con especial referencia en el Derecho español. Este principio predomina en el órgano colegiado de la sociedad anónima y se materializa en el acuerdo que deriva de una uniformidad de intereses comunes de los accionistas que declaran su voluntad frente al orden del día, aunque no siempre las declaraciones se emiten en mismo sentido. El cómputo de las acciones no parte de todo el capital de la sociedad, sino sobre las acciones presentes o representadas en la junta con derecho a voto, siendo generalmente la mitad más uno. Esta mayoría puede ser reforzada y los estatutos podrán regularlo. Se podrán tomar en cuenta los votos en blanco, disidentes, más no las acciones propias, obligando la mayoría a la minoría, excepto que se oponga y se ejercite la acción de impugnación de los acuerdos sociales. En Nicaragua se sigue el sistema de mayoría absoluta por vinculación al quórum de asistencia.

Palabras Clave: accionista, junta general, mayoría, voto

\section{Abstract}

The study of the principle of most general shareholder together allows us to perform a detailed analysis of the provisions contained in the Code of Commerce of Nicaragua and compare it with the contemporary doctrine and foreign legislation with special reference to the Spanish law. This principle predominates in the collegial body of the corporation and is embodied in the agreement stems from a uniform common interests of the shareholders who declare their will against the agenda, but not always the statements are made in the same direction. The computation of the shares not part of the entire capital of the company, but on the shares present or represented at the meeting voting, generally being half plus one. This majority can be strengthened and the statutes may regulate it. They may be taken into account blank votes, dissenting, but not one's own actions, forcing the majority to the minority, except that opposes the action and challenge corporate agreements is exercised. In Nicaragua the absolute majority system is followed by links to the quorum.

Key Words: Shareholder, General Meeting, majority, vote

Fecha de Recepción: miércoles 04 de mayo 2016

Fecha de Aprobación: lunes 21 de octubre 2016
* Profesor Titular de la Facultad de Ciencias Jurídicas, Universidad Centroamericana de Nicaragua, Tel.(505) 82577949

Email:cristianrobleto@gmail.com, Managua, Nicaragua. Rotonda Rubén Darío 150 metros al oeste, UCA, Edificio B, Facultad de Ciencias Jurídicas. 


\section{Introducción}

El presente trabajo de investigación tiene como objetivo exponer algunos de los principales aportes que resultaron del proceso investigativo de la tesis doctoral titulada "La adopción de los acuerdos sociales por la junta general de accionistas en el Derecho nicaragüense" en el tema que aquí desarrollamos sobre el principio de mayoría de la junta general de accionistas analiza la situación actual derecho vigente y expone soluciones jurídicas dadas por el mismo sistema, tomando como base la forma de determinar y calcular la mayoría considerando lo pertinente a la libertad contractual que permite aumentar el capital requerido.

\section{Metodología}

Metodológicamente se realiza un análisis cualitativo, que parte de lo simple a lo complejo, sobre el principio de mayoría, sistematizada por la doctrina extranjera más relevante que abordan la materia y ello nos permite identificar las pautas a seguir para proponer soluciones jurídicas respecto a las leyes vigentes de Nicaragua, así como para presentar a manera de citas los comentarios del Anteproyecto del Código de Comercio.

En el primer tema se analiza el principio de mayoría desde la óptica de su caracterización como fórmula requerida en la junta generalmente constituida legalmente en la cual cada socio expresa su voto creando una posición respecto al acuerdo, siempre que no sea contraria la ley y a los estatutos sin lesionar los intereses sociales. Este principio presupone la existencia de una uniformidad de vínculos dirigidos al voto.

El segundo tema expone como se calcula la mayoría en la junta considerando lo que sucede con los votos en blan$\mathrm{co}$, los disidentes y los votos nulos. Asimismo se continúa con los criterios para calificar el voto como mayoría ordinaria identificando si se trata de mayoría simple o absoluta. Finalmente, se hace un breve análisis del acuerdo unánime de celebrar una junta general universal, diferenciándola del ejercicio del derecho de voto una vez constituida.

\section{Disposiciones Generales del Principio de Mayoría en el Código de Comercio de Nicaragua, la doctrina contemporánea y la legislación extranjera.}

\section{Caracterización del principio de mayoría}

Los artículos 124.14, 254 y 262 del Código de Comercio de Nicaragua [publicado en la Gaceta Diario Oficial, No. 248, del 30 de octubre de 1916; (en lo sucesivo, CC de Nicaragua)] reconocen el principio de mayoría ${ }^{1}$ aceptando que las deci-

1-El artículo 2120-8, núm. 3 del Anteproyecto del Código de Comercio de Nicaragua, reconoce el principio de mayoría necesaria para la adopción de los acuerdos sociales. En ese sentido, se pronuncia el artículo 2161-64 del siones de junta general se tomarán con más de la mitad de los votos para la junta ordinaria y la mitad de los votos por lo menos en otro tipo de juntas

Se observa en las disposiciones citadas que no se hace la diferencia si se trata de una mayoría simple o absoluta. Con ello no se aclara sobre qué base calcular la mayoría referida en ambos supuestos.

De acuerdo con Díaz Moreno (2015b, pp. 116-127), Sánchez Calero y Sánchez-Calero Guilarte (2013, p. 494), Cruz Rivero (2013, pp. 499-504), Iglesias y García de Enterría (2012, pp. 462-463), Peña Nossa (2011), Broseta Pont y Martínez Sanz (2011, p. 420), Sánchez-Calero Gilarte (2010, p. 244), Sánchez Linde (2010, p. 1351), Mesa Tejeda (2010, pp. 111-125), Rodríguez Artigas (2009, p. 16), Sánchez Linde, M (2009a, pp. 35-39), Boquera Matarredona (2008, p. 166), Fernando de la Gándara (2007, p. 532-562), Calaza López (2003, pp. 100-150), Uría, Menéndez y García de Enterría (1999, p. 829), Díaz-Pintado (1994,p. 1101) y Vicent Chuliá (1991, p. 608) el principio mayoritario es la fórmula que se refiere a que una junta general de accionistas constituida y cumpliendo con los requisitos legales y estatutarios, cada socio expresa su voto creando una posición de mayoritaria, resultando el acuerdo válido. Esta expresión de voluntad emitida por el voto se transforma en la decisión de la sociedad si la junta general resuelve sobre asuntos de su propia competencia que a ello responde la existencia del órgano social ${ }^{2}$.

En consecuencia, todos los accionistas quedan obligados, aunque no hayan concurrido o hayan votado en contra ${ }^{3}$.

mismo Anteproyecto, al referirse que las decisiones de juntas se tomarán por el voto favorable de la mayoría de ellos, según lo que regulen los estatutos y se computan con base al capital social pagado. También deja claro que las decisiones que se toman en el órgano obligan a todos los socios, incluyendo los que votaron en contra y los ausentes. Observamos que la intención de la comisión redactora es correcta, pero cometen el error al señalar que para la votación se tomará en cuenta el capital pagado que para nuestro punto de vista deberá decir capital suscrito con derecho de voto.

2- Olivencia Ruiz (2005, p. 97) ya manifestaba que el principio de mayoría como acto colectivo se caracterizaba como un acto pluripersonal, no plu rilateral, porque se refiere no a un concepto técnico de parte en Derecho, sino que supone la participación de una pluralidad de participantes que integran una comunidad de intereses de igual naturaleza y que intervienen en virtud de una misma legitimación.

3-Polo Sánchez (1973, pp. 201 y siguientes) en el estudio sobre el régimen de quórum y de mayoría de los órganos colegiados, planteaba la existencia de un problema en relación con las abstenciones, votos en blanco o votos nulos, señalando que tan acuerdo es la propuesta favorable como la que rechaza la misma. En ese sentido, calificar de acuerdo el que tiene un sentido negativo no es sólo rigurosamente exacto en el orden lógico, por cuanto es susceptible de impugnación. En este caso, se puede entender que no hay mayoría porque son más los votos negativos sumados a las abstenciones (o votos nulos o en blanco), a pesar de que los positivos superen los primeros, se le atribuye a la abstención, al voto nulo o al voto en blanco un valor decisorio que por su propia condición no tiene ni debe tener. Para evitar este resultado contradictorio, no hay otro remedio que prescindir de las abstenciones, votos en blanco, votos nulos. De manera que si los votos negativos superan a los positivos o viceversa habrá acuerdo positivo o negativo, sin que se tomen en cuenta las abstenciones, 
Este acuerdo colectivo es la voluntad de la sociedad que será siempre un requisito imperativo para llevar a cabo una gestión de operación con vinculación a la sociedad, entendido al margen de los supuestos puntuales aceptados por la ley, en donde no necesita acuerdos mayoritarios para adoptar acuerdos sociales, así encontramos en la sociedad anónima unipersonal, donde las decisiones de un socio único no provienen de una decisión de mayoría precedida de una votación. En virtud de la fórmula de la mayoría, el Derecho entiende que existe un desacuerdo ante una posición que ha manifestado un porcentaje mayoritario.

Consideramos que lo expuesto por los autores citados es coincidente con nuestro criterio del Derecho positivo vigente, respecto al significado y alcance de la regla sobre el principio de mayoría de la junta general, argumento que tiene su expresión más significativa en el artículo 124.14 CC de Nicaragua, referido a la sumisión del voto de la mayoría. Aunque no lo define pero es la base para concluir si se trata de una mayoría en sentido positivo aceptando los acuerdos y en sentido negativo por la suma de los votos en contra. Dicho criterio se materializa en los artículos 254 y 262 del CC de Nicaragua. De esta manera, podemos concluir que los votos tendrán un sentido jurídico respecto a su eficacia de los acuerdos de mayoría. Asimismo conviene señalar que la extensión y vinculación de los acuerdos sociales abarcan a todos los accionistas, aunque no hayan participado ni activa ni pasivamente, vinculación que no tiene alcance a los terceros, ni a los socios cuando actúan como terceros, dando de esta manera una relación directa y legal con la sociedad anónima, cuya función es dar seguridad jurídica a lo acordado por el órgano social. En ese sentido el artículo 124.14 CC, reitera que en el contrato social se señalará el modo de formar la mayoría para que sus resoluciones sean obligatorias.

Según manifiesta Girón Tena (1952, p. 300) desde el punto de vista genérico el principio democrático de mayorías presu-

puesto que no cabe hablar de mayoría, si ni siquiera existe en sentido relativo. En este último caso, al no haber acuerdo, se llega a las mismas consecuencias prácticas que si el acuerdo hubiera sido negativo, pero este resultado es inevitable, porque sin mayoría relativa o lo que es lo mismo, la mayoría relativa corresponde a las abstenciones, no habrá acuerdo. No es lo mismo, que no haya acuerdo porque la abstención superen a los votos positivos o negativos, que sumar las primeras a los últimos. Con relación a los votos nulos, no puede contarse en absoluto, no es equiparable a la abstención para los efectos de la formación de las mayorías relativas y por lo que dice al voto en blanco, en tanto sea similar a la abstención. Consideramos que la diferencia entre el voto en blanco o la abstención, es que el que se abstiene y puede ser considerado disidente, respecto a la votación de la misma, lo cual es importante, respecto al derecho de separación, pero con relación a la impugnación (esto tenía antes más relevancia que ahora con el nuevo artículo 206 LSC de España, lo que no acontece con el que vota en blanco. En relación con el voto nulo, es evidente que el accionista que lo emite no podrá impugnar el acuerdo ni ejercitar el derecho de separación. En todo caso, la presencia de los accionistas cuyos votos sean nulos sólo pueden ser útil a los efectos de la formación del quórum de presencia, lo que en opinión De la Cámara (1979, pp. 275-300) no ocurre siempre, sino que dependerá de la causa a que el voto nulo obedezca.

ISSN: 2309-5296 pone la existencia de una uniformidad de intereses que es lo que aglutina los votos, de lo contrario se produce un defecto de legitimación para disponer. Partiendo de la opinión expresada por el citado autor la uniformidad de intereses comunes es desde nuestro punto de vista un elemento esencial del principio mayoritario, puesto que deberá existir un grupo de accionistas que declaren su voluntad a los puntos del orden del día, aprobando o desaprobando cada aspecto ${ }^{4}$. Con lo anterior no quiere decirse que siempre la declaración de voluntad será en un mismo sentido, pero sí que para que el acuerdo sea eficaz y pueda ejecutarse deberá contar con los votos necesarios para cada tipo de junta y prevalezca el cumplimiento de los derechos de los socios. Por otra parte, la decisión mayoritaria puede consistir en desaprobar la propuesta y discutido en las deliberaciones de acuerdo al orden del día.

Surgen dos cuestiones atenientes a la disciplina reguladora de los acuerdos que cobran particular importancia según los planteamientos expuestos por Fernández de la Gándara (2010, pp. 622-647), y Sánchez Calero y Sánchez-Calero Guilarte (2013, p. 484) en el contexto del sistema español, siendo los siguientes:

a). La deliberación y decisión recae en asuntos que competencia de la junta general de accionistas, constituyendo una doble condición de dicho órgano [artículo 159 del Real Decreto Legislativo 1/2010, de 2 de julio, por el que se aprueba el texto refundido de la Ley de Sociedades de Capital. Publicado en BOE No.161, de 03 de Julio de 2010 (en lo sucesivo, LSC deEspaña)].

b). Lo referido a la determinación y cómputo de la mayoría requerida para la adopción de los acuerdos. El artículo 159.1 de LSC de España expresa que los accionistas reunidos en junta general decidirán en mayoría legal o estatutariamente, por lo que se deduce que no se considera admisible a los acuerdos unánimes por decisión estatutaria, por ser contraria al precepto legal citado.

Desde el punto de vista de los autores citados las dos cuestiones sobre la competencia y el cómputo de la mayoría en el contexto nicaragüense, son dos temas que permiten identificar si cabe o no la toma de decisión sobre los puntos deliberados y resueltos en el órgano de la sociedad (artículo 203 CC), por cuanto ambos son elementos que delimitan el alcance del acuerdo, puesto que no caben acuerdos válidos de mayoría si los asuntos no son competencia de la junta, en cualquier caso, serán objetos de impugnación por ser considerados nulos e inexistentes (artículo 261 CC de Nicaragua).

4- Los socios pueden pactar voluntariamente, limitar su libertad de voto y obligarse con otros socios votar en un determinado sentido. De manera que los socios que lo han suscrito condicionan su actuación en la junta general. Lo característico de los pactos parasocietarios, como el sindicato de votos, es que no se integran en el ordenamiento de la persona jurídica, sino que permanecen en el recinto de las relaciones de quienes suscriben (Sánchez Linde, 2009a, p. 66; Madina, 2004, pp. 83-90; Páz- Ares; 2003b, pp. 19-42; Pérez Mariones, 1997, p. 88; Fernández del Pozo, 1992, p. 88)

Revista de Derecho. Vol. 37, No. 1, Año 2016|-53 
Comenta Fernández de la Gándara (2010, pp. 622-647) siempre con relación al artículo 159.1 LSC de España que nada dice el legislador si se refiere a la mayoría en sentido real o personal. Cabe interpretar que por referirse a los accionistas los redactores del artículo 48 de la LSA de 1951 habrían consagrado el principio de mayoría personal; por lo tanto, la ambigüedad formulada había suscitado diversas opiniones respecto a la mayoría que nada tiene que ver con el número de votos ni con los votos emitidos, sino con los votos, correspondiente al total de las acciones concurrentes a la constitución de la junta ${ }^{5}$. Es decir, se trata de la mayoría simple ${ }^{6}$ de los votos correspon-

\begin{abstract}
5- De la Cámara Álvarez (1979, p. 222) y Polo Sánchez (1973, pp. 201 y siguientes) refiriéndose a la mayoría comentaba que hay que referirse a la mayoría de acciones presentes o representadas en la junta y no a la totalidad de los circulantes. En todo caso, la mayoría no debe computarse sobre el total de votos incorporados a todas las acciones en circulación, sino sólo sobre los correspondientes a las acciones presentes o representadas en la junta. Sería un contrasentido, que la mayoría hubiera de computarse sobre todos los votos que representa el capital social, y sin embargo, que la junta pudiera quedar válidamente constituida en segunda convocatoria, cualquiera que sea el número concurrente. Por otra parte, los estatutos determinan la forma de deliberar y de tomar acuerdos. Siendo entonces que la mayoría equivalente a la mitad más uno, en otras palabras habrá mayoría cuando voten a favor más de la mitad de los votos computables en la asamblea, pero es posible que los estatutos sigan otro criterio. La mayoría estatutaria puede ser reforzada, bien porque se exija la conformidad de una mayoría especial de los votos correspondientes a las acciones presentes o representadas en la junta, bien porque se pida la conformidad de la mayoría absoluta o mayoría reforzada, respecto a la totalidad de las acciones. En todo caso, se está ante dos limitaciones en los estatutos: a) no podrá exigirse una segunda convocatoria con una mayoría que supere el quórum de asistencia requerido; b) no se puede exigir la unanimidad para la adopción de los acuerdos, con excepción de decisiones que vulneren los derechos irrevocables de los accionistas.
\end{abstract}

6- El artículo 2368.1 del Código Civil en el Derecho italiano dispone que la junta general ordinaria adopta sus acuerdos por mayoría absoluta, siendo necesario la presencia de socios que representen al menos, la mitad del capital social, en caso de junta general extraordinaria, es preciso el voto favorable de los socios que representen más de la mitad del capital social. En ese sentido, no hay duda con relación a la mayoría necesaria, sin embargo no queda claro que se entiende por mayoría absoluta. Una gran parte de la doctrina entiende como la mitad más uno de los votos correspondientes a las acciones con derecho de voto concurrente en la junta general (Brunetti, Minervini, Romano-Pavoni, Sena, Galgano, Farri, Ferrara, citados por Casado de Pablos, 2002, pp. 362-392). Para otro sector minoritario de la doctrina, la mayoría absoluta se debe tener sólo en cuenta los votos favorables y los votos contrarios para un determinado acuerdo; si prevalecen los primeros, el acuerdo es aprobado, mientras que si prevalecen los segundos, el acuerdo es rechazado, las abstenciones no cuenta (Fré, Branca, Dalmartello, Sacchi, Colombo y Portale, citados por Casado de Pablos, 2002, pp. 362-392). Asimismo, la jurisprudencia italiana está dividida, encontrándose algunas sentencias que indican que la mayoría absoluta se calcula teniendo en cuenta a todos los socios presentes que tengan derecho al voto, pero por el contrario, existen pronunciamientos que determinan que la mayoría debe ser calculada de acuerdo con los socios presenten y votantes, prescindiendo de aquellos que se ausentaron. En el caso del Derecho español tras la reforma de la LSC de España según Ley 34/2014 del 3 de diciembre de 2014 en las sociedades anónimas, los acuerdos sociales se adoptarán por mayoría simple de los votos de los accionistas presentes o representados en la junta, entendiéndose adoptado un acuerdo cuando obtenga más votos a favor que en contra del capital presente o representado. Para la adopción de los acuerdos a que se refiere el artículo 194 de la LSC si el capital presente o representado supera el cincuenta por ciento bastará con que el acuerdo se adopte por mayoría absoluta. Sin embargo, se requerirá el voto favorable de los dos tercios del capital presente o representado en la junta cuando en segunda convocatoria concurran accionistas que representen el veinticinco por ciento o más del capital suscrito con derecho dientes a más de la mitad del capital presente y representado, sin tener en cuenta si está o no desembolsado, sin perjuicio de la mayoría cualificada o mayoría reforzada ${ }^{7}$

de voto sin alcanzar el cincuenta por ciento. Los estatutos sociales podrán elevar las mayorias previstas en los apartados anteriores. En el Derecho francés, la Ley núm. 66/537 de 24 de julio de 1966, sobre las sociedades comerciales, relacionado con la junta, se refiere a las mayorías necesarias para adaptar los acuerdos en los artículos 155 y 153. En el caso de junta general ordinaria el artículo 155 establece que es necesaria la mayoría de votos de que disponen los accionistas presentes o representados, y en el caso de junta general extraordinaria, el artículo 153 requiere la mayoría de dos terceros de votos de que disponen los accionistas presentes o representados. Esta redacción es clara y pacífica a la hora de interpretar las mayorías necesarias para adoptar los acuerdos. Son válidas los votos por correspondencia. Asimismo, la doctrina francesa da un valor de negación a las abstenciones, los votos en blanco y nulos. En el Derecho alemán, la antigua Ley sobre Sociedades Anónimas y Comanditarias por acciones de 1937, exigía en su 113 la mayoría simple, exigencia que ha recogido el artículo 133 de la nueva ley de acciones de 5 de septiembre de 1965, numeral 1, que los acuerdos de junta precisan de la mayoría de los votos emitidos (simple mayoría de votos) a menos que la ley o estatutos no exijan una mayoría más alta u otros requisitos. En ese sentido, la propia ley determina cómo debemos efectuar el cálculo de la mayoría, no se computan los votos de quienes se alejan de la junta antes de la votación. Para el Derecho suizo, el Artículo 703 del Código Federal de las Obligaciones, de 30 de marzo de 1911, modificado en 1936, señala que la junta general adoptará sus acuerdos, por mayoría absoluta de los votos correspondientes a las acciones representadas, salvo que la ley o estatutos dispongan otra cosa. Se computan los votos válidamente emitidos y la totalidad de votos correspondiente a las acciones concurrentes en la junta, y tratándose de mayoría absoluta, es necesario la mitad más uno de dichos votos. Concluye Casado de Pablo (2002, pp. 362-392) que en el Derecho comparado, fluctúan entre computar la mayoría-mitad más uno-sobre los votos presentes o representados (Italia, Francia, Suiza) y computar la mayoría sobre los votos realmente emitidos, en el caso de Alemania. Existen distintas nociones sobre la expresión mayoría, como se ha estudiado, encontrando el termino de mayoría absoluta, presupone que los votos o pareceres coincidentes sobrepasan la proporción de la mitad con relación al total computable. En consecuencia, parece más adecuado definir la mayoría absoluta como el número entero inmediatamente superior a la mitad de la base de cálculo, en cuya definición se comprenden ambos casos. La mayoría relativa o simple, se identifica con la determinación por el mayor número de votos iguales o coincidentes en un mismo sentido respecto al tema sometido a votación, sin superar necesariamente la mitad del total de ellos. La mayoría cualificada, supone toda mayoría superior a la mayoría absoluta que no alcance o suponga fácticamente la unanimidad (Casado de Pablos, 2002, pp. 362-392).

7- Hernando Cebriá (2011, p. 99) comenta que el principio mayoritario nace como finalidad de dotar a la sociedad capitalista de una mayor funcionalidad, mediante la obtención de determinados consensos para la toma de decisiones en la junta general. La posible elevación de la mayoría por vía estatutaria, permite que puedan existir sociedades anónimas donde la regla de la mayoría sea incluso más cualificada o reforzada que en las sociedades limitadas. El carácter de un contrato de sociedad de colaboración abierta permite amoldar a la sociedad a la voluntad de los socios de acuerdo al esquema legal imperativo. En todo caso, el sistema legal vigente en España excluye el sistema de la unanimidad en el artículo 200 LSC. Se pretende en este caso dotar de funcionalidad a la sociedad haciendo sus estructuras se adapten al entorno económico y social. En las sociedades paritarias, de facto, se deduce la necesidad de adoptar los acuerdos por unanimidad. Dicha afirmación pareciera cierta, pero no lo es, en relación con el principio mayoritario, que impide acuerdos unánimes. Por otra parte, Vicent Chuliá (1991, p. 322) ya comentaba sobre los diversos conceptos de mayoría, refiriéndose al principio de mayoría de capital, y no de personas. La terminología de mayoría no deduce unanimidad, siendo la primera causa de confusión. Se denomina mayoría absoluta a la mínima 
Comentan Broseta Pont y Martínez Sanz (2011, p. 420) que no obstante, la mayoría puede reforzarse en los estatutos, aunque siempre sin llegar al límite de la exigencia de la unanimidad, pues supondría ir en contra del principio de mayoría que ha de regir el funcionamiento de la junta.

Podemos concluir que el principio de mayoría es requisito esencial para la toma de decisión de los acuerdos de junta general de accionistas, corresponde entonces la voluntad de la sociedad y obliga a todos los accionistas presentes, disidentes y ausentes.

Este principio de mayoría persigue el cumplimiento del interés social de la sociedad y desde el punto de vista de la sociedad anónima no es factible regular la toma de decisiones con base en la unanimidad del voto, pudiendo causar bloqueo de la junta. Lo que la doctrina no deja claro es si la decisión de mayoría se basa en mayoría absoluta o mayoría simple, por lo que según el artículo 254 debe entenderse como mayoría absoluta y el artículo 262 sobre los acuerdos de junta con quórum de constitución reforzado como mayoría cualificada que es una modalidad de la mayoría absoluta.

Las razones que nos llevan a esta conclusión es que se considera absoluta porque para ellos hay que partir del artículo 253 CC de Nicaragua que se refiere a los requisitos del quórum de los asistentes presentes con derecho a voto y considerando que el artículo 254 CC no se refiere a la modalidad de mayoría al señalar que las decisiones se toman con la más de la mitad de los votos, entonces observamos que ambas disposiciones están vinculadas, concluyendo en la mayoría absoluta al igual que lo dispuesto en el artículo 262 CC.

\section{Cómputo de la mayoría}

Los artículos 124.14, 254 y 262 del CC de Nicaragua sobre el cómputo de la mayoría de los accionistas en la junta se aplicará el de aquellos socios con derecho de voto, independientemente que la declaración de voluntad de cada accionista cambie al momento de ejercer el voto, formando una minoría que tiene el sustento técnico para calificarlo como tal, excepto cuando en segunda convocatoria comparezcan los accionistas que concurran a la sesión y se aprueben los acuerdos con el mínimo legal acordado para cada junta.

que se puede calcular a la vista de una determinada colectividad, a priori y para todos los casos. Lógicamente, tal mayoría es siempre, la mitad más uno, que puede ser de cabeza o de capital. La base del cálculo de esta mayoría absoluta puede ser la de socios o capital presente. Frente a la noción de mayoría absoluta están: 1) la de mayoría reforzada $(2 / 3,3 / 4$, etc) que se computan igualmente sobre la totalidad de socios o capital o sobre socios o capital presentes, pero puede venir precisada por los estatutos; 2) la mayoría absoluta de los votos presentes o representados; 3) Mayoría simple, o más de la mitad de los votos válidamente expresados; 4) Mayoría relativa, o mayor número de votos expresados a favor de una propuesta o candidato (aunque no alcance a la mitad de los votos válidamente expresados). Este tipo de mayoría es el mayor número de personas o de cifras de capital que se expresa o vota en un determinado sentido, y su denominación indica que sólo a posteriori de la votación es posible determinarla.
En cuanto al cómputo de la mayoría ${ }^{8}$, tanto la conducta del abstencionista como los votos en blanco ${ }^{9}$, serán tenidos en cuenta para el cálculo de la mayoría requerida para la adopción de los acuerdos, en la medida en que contrariamente a lo que sucede con los ausentes unos y otros colaboran en la formación de voluntad ${ }^{10}$.

En consecuencia, la mayoría referida en el artículo 159 LSC de España, se calcula sobre los votos correspondientes a los accionistas presentes y representadas en cada junta; de ahí la imposibilidad de incluir votos de accionistas morosos, los conferidos por las acciones cuyos, titulares no posean el número exigido por los estatutos para asistir o no consigan agru-

8- Con relación al cómputo de la mayoría Olivencia Ruiz (2014, pp. 799817.) señala que el principio de mayoría no es una regla única, sino que se estructura en distintas fórmulas aritméticas de computar los votos y determinar cuándo alcanza esa mayoría en el órgano colegiado. Por eso se habla de mayoría simple, relativa, cualificada, reforzada, que oscilan en una diversidad, según el tipo de sociedad. En la vida de la sociedad como en la política, la mayoría se computa en virtud de una operación matemática. Por su parte Cabanas Trejo (2014, p. 8) aclara que Ley 31/2014 de España, pone fin a las dudas que vienen de LSA de 1951 sobre el principio de mayoría, pero sin dejar claro la forma del cómputo, es decir, si era una mayoría relativa (mayor número de votos a favor que en contra) o absoluta (más de la mitad de los votos presentes o representados en la junta general) en definitiva qué consideración deberían tener los votos nulos, en blanco y las abstenciones. En esta redacción el artículo 201.1 establece la regla de la mayoría simple. De manera que el acuerdo se adopta cuando se tenga más votos a favor que en contra del capital presente o representado. Asimismo aclara la mayoría del quórum reforzado del artículo 194 LSC. Si el capital presente o representado supera el $50 \%$ bastará que el acuerdo se adopte por mayoría absoluta. Sin embargo se requiere el voto favorable de los 2/3 del capital presente o representado en la junta cuando en segunda convocatoria concurran accionistas que representen el $25 \%$ o más del capital suscrito con derecho de voto sin alcanzar el $50 \%$.

9- Un parte de la doctrina (Sánchez Calero, 2007b, p. 53 y Uría, Menéndez y Muñoz Planas, 1992, p. 142) entienden que el acuerdo adoptada cuando votan a favor de lo propuesto la mitad más uno de los socios concurrentes a la junta general. Se cuentan los votos negativos, las abstenciones, votos en blancos o votos nulos. La mayoría se cuenta sobre todo los votos emitidos. Quienes apoyan está corriente opinan que los votos nulos y en blanco son votos no favorables o negativos. De manera que si los votos sumados a los contrarios a la propuesta superan a los votos favorables no habrá acuerdo (Díaz Moreno, 2015b, pp. 116-127, Boquera Marredona, 2008, p. 167). Otros autores (Rodríguez Artigas, 1995, p. 633; Recalde Castells, 1996, p. 52 y siguientes, y Esteban Velasco, 1998, p. 255) consideran que el mayor número de votos favorables frente a los adversos constituye la mayoría necesaria para la adopción válida de un acuerdo, es decir, más votos positivos que negativos, mayoría simple. Para esta corriente no deben computarse los votos nulos, en blanco y las abstenciones para el cálculo de la mayoría, pues de lo contrario, dichos votos se computarán negativos y no se consideran a cada una de las categorías el valor que expresa el votante o de quien se abstiene. En conclusión, Boquera Matarredona (2008, p. 168) señala que conviene regular estatutariamente el modo de adoptar los acuerdos por la junta general. Nada impide que los estatutos refuercen las mayorías requeridas para adoptar algunos acuerdos y exijan que vote a su favor un determinado porcentaje de capital social o un porcentaje superior a un tanto por ciento de capital social. Independientemente de las opiniones anteriores cabe advertir que en el artículo 201.1 LSC de España es clara al afirmar que los acuerdos se adoptarán con la mayoría simple.

10-La STS de España: 19-7-2005 (64, 2005), declaró que una vez constituida la junta de accionistas, con el quórum de constitución, los acuerdos se aprueban por mayoría; el socio que se ausenta no se presume como un voto a favor o en contra, sino como abstención y si es determinante para formar mayoría, el acuerdo no queda aprobado 
parse para conseguir esa cifra de capital. Se consideran en algunos casos el capital concurrente y computable a efectos de calcular la mayoría, aun teniendo suspenso los derechos de asistencia y voto, las acciones propias ${ }^{11}$ en poder de la sociedad o que estén poder de sociedades filiales, incluyendo las recibidas en prenda o bajo otra forma de garantía (artículo 148, b LSC) (Sánchez Calero, 2015, p. 271; Ruiz Rojas, 2014, pp. 19-35; Boldó Roda, 2013, p.176; Fernández de la Gándara, 2010, p. 647-659; García de Enterría, 2002, p. 1703 y siguientes; Sánchez Linde, 2009b, p. 219-248; Uría, Menéndez y Muñoz Planas, 1992, pp. 116-117; Muñoz de Dios, 1985, p. 877).

Considerando lo señalado por autores citados, se puede decir que para el Derecho nicaragüense al computar la mayoría se tomarán en cuenta los votos presentes, los disidentes, los votos en blanco, más no las acciones propias y una vez sometido a votación lo decidido obliga a todos independientemente que los accionistas formen parte de los votos de minoría.

En ese sentido, la mayoría obliga a la minoría, excepto que se opongan a los acuerdos y ejerciten el derecho de protesta o impugnación de los acuerdos sociales conforme el artículo 261 del CC y el tribunal los declare nulo. Por otra parte, consideramos que los accionistas que tengan suspenso su derecho de voto, no se tomarán en cuenta para el cómputo, pero los efectos del acuerdo de junta serán aplicables para todos independientemente de la condición en la que se encuentren.

Cuando estamos ante la presencia de limitaciones estatutarias, es preciso determinar la incidencia que ésta condición establece sobre la forma del cómputo en la adopción de los acuerdos.

Por lo tanto, considero que aplicando lo dispuesto en el segundo párrafo del artículo 254 CC de Nicaragua, es decir, cuando se pacte estatutariamente, en la junta general que asista un socio afectado con dicha limitación es necesario que se determine previamente el número de votos que puede ser efectivamente emitidos por los accionistas presentes o representados y calcular sobre esta base la mayoría legal 0 estatutariamente para la adopción del acuerdo social de que se trata. Es decir, el cómputo se hará con el derecho de voto que sean necesariamente emitidos en función de la cifra del capital concurrente, excluyendo las acciones que por situar al accionista por encima del porcentaje de capital, no puedan ser ejercitadas.

\section{Determinación de la mayoría}

\footnotetext{
11-Vázquez Cueto (1995, p. 508) señala que las acciones propias quedan neutralizadas en correspondencia con su lógica jurídica, ya que difícilmente pueden tener la posibilidad del ejercicio del derecho por la sociedad emisora, tales como el de impugnación de acuerdos, el de asistencia a la junta, el de información, etc.
}

Este criterio de calificar el voto como mayoría ordinaria en el ámbito del Derecho nicaragüense es distinto al sistema español que se refiere más bien a la mayoría simple y en su caso a la cualificada ${ }^{12}$, por cuanto requiere para que haya acuerdo, más de la mitad de los votos ${ }^{13}$ (artículo 254 CC). Para los casos especiales se requiere el voto favorable de socios que representen la mitad del capital social por lo menos (artículo 262 CC).

Por otra parte, encontramos que en el segundo párrafo del artículo 254 del CC de Nicaragua, se admite que la determinación del cómputo para calcular la mayoría puede ser modificada en el contrato social y estatutos, es decir, se permite que éste aumente a un porcentaje mayor que el regulado. Sin embargo, la disposición citada no establece un límite de hasta dónde ampliarlo. En consecuencia, los estatutos pueden elevar las mayorías legales necesarias para adoptar algunos acuerdos o para todos.

12- En la Ley General de Sociedades del Perú, en el artículo 63 [Ley No. 266787 del 19 de noviembre de 1997, promulgado el 5 de diciembre de 1997 (en lo sucesivo, LGS del Perú)], señala que la adopción de los acuerdos requiere el voto favorable de la mayoría absoluta de las acciones representadas. Igualmente, se requiere el voto favorable de la mayoría absoluta de las acciones suscritas para que la asamblea pueda modificar el contenido del programa de fundación. El artículo 61 de la Ley de Sociedades Anónimas de Chile [Ley No. 18046, publicada y promulgada el 22 de octubre de 1981 (en lo sucesivo, LSA de Chile)], los acuerdos se tomarán en mayoría absoluta de las acciones presentes o representadas con derecho al voto; asimismo, el artículo 67, establece que los acuerdos de la junta extraordinaria de accionistas que impliquen reformas a los estatutos sociales o el saneamiento de nulidad, deberá ser adoptado con la mayoría que determinen los estatutos, en las sociedades cerradas, no podrá ser inferior a la mayoría absoluta. Finalmente requiere el voto conforme a las dos terceras partes de las acciones emitidas con derecho a voto, los acuerdos relativos a los casos señalados en el artículo 67. El artículo 243 de la Ley de Sociedades Comerciales de Argentina [Ley No. 19.550, Decreto $N^{\circ} 841 / 84$ B.O. 30/03/1984 (en lo sucesivo, LSC de Argentina)], establece las resoluciones de junta que se emitan en asamblea ordinaria, tanto en primera convocatoria como en segunda serán tomadas por mayoría absoluta de los votos presentes que puedan emitirse en la respectiva decisión, salvo que los estatutos exijan un mayor número. En las asambleas extraordinarias las resoluciones en primera y en segunda convocatoria serán tomadas por mayoría absoluta de los votos presentes, salvo que los estatutos dispongan un número mayor. En la Ley de Sociedades Comerciales de Uruguay, en su artículo 356 [Ley No. 16.060, publicada en el Diario Oficial el 1 de noviembre de 1989, No. 22977 (en lo sucesivo, LSC de Uruguay)], dispone que las resoluciones de las asambleas serán adoptadas por mayoría absoluta de votos de los accionistas presentes, salvo que la ley o el contrato exijan mayor número. Se exigirá la mayoría del capital con derecho a voto para resolver los casos previstos en el artículo 330, la emisión de nuevas acciones preferidas salvo previsión expresa del estatuto, la alteración en las preferencias, ventajas o condiciones de rescate o amortización y la participación en grupo de interés económico o en otras sociedades (artículos 47 a 49). Quien vote en blanco o se abstenga de votar se reputará como que ha votado en contra, a todos los efectos de esta ley.

13- El artículo 2161-25 del Anteproyecto del Código de Comercio de Nicaragua, propone que en primera convocatoria los acuerdos se tomarán con mayoría absoluta de los participantes de los votos favorables, salvo disposición en contrario, pudiendo pactar mayorías superiores, pero jamás inferiores a lo señalado en la norma. Para la segunda convocatoria se adoptarán los acuerdos con el voto favorable de la mayoría absoluta con derecho a voto de los participantes, aun cuando la asamblea se constituya con un solo participante. 
En el sistema español la determinación del quórum mayoritario se efectúa con relación a los accionistas presentes o representados, siendo necesario el voto favorable de más votos a favor que en contra. En la determinación de la mayoría, se toman en cuenta los votos favorables emitidos válidamente y se califica la mayoría como simple (artículo 201.1 LSC de España $a^{14}$ ). Según las reformas de la Ley 31/2014 de España, en la LSC se consideró muy importante que los socios puedan pronunciarse con sus votos sobre materias sometidas a su consideración, sin que la dispersión de las materias distorsione el resultado de la votación, por ello se exige que se vote separadamente aquellos asuntos que sean sustancialmente independiente, aunque figuren en el mismo orden del día: el nombramiento, ratificación, la reelección o separación del administrador, la modificación de estatutos sociales, la de cada artículo o grupo de artículo que tengan autonomía propia (Cabanas Trejo, 2014, pp. 8 y 9).

En este supuesto del artículo 201.1 de LSC de España nos parece una solución acertada, que ya venía siendo respondida por la jurisprudencia española y que comparando esta medida con el sistema nicaragüense nos parece que es correcta y viene a responder muchas dudas sobre el tipo de mayoría que responde el artículo $254 \mathrm{CC}$ correspondiente a la mayoría absoluta considerada a partir del capital social presente en la junta general y se computan los votos válidos, y si en los estatutos se contempla el sentido de los votos en blanco y las abstenciones, entonces, podrán ser computados para formar la mayoría (artículos 124.14, 254 y 262 CC), excepto que el contrato social guarde silencio al respecto y no constituyan manifestaciones ni a favor ni en contra de la propuesta.

En relación con la adopción de los acuerdos sobre los asuntos referidos en el artículo 194 de la LSC de España ${ }^{15}$, es

\footnotetext{
14- Díaz Moreno (2015b, p. 135) señala que según dispone el apartado 1 del artículo 201, el significado de la expresión contenida en la norma añade que se entenderá adoptado un acuerdo cuando la correspondiente propuesta obtenga más voto a favor que en contra del capital presente o representado. La mayoría simple es por lo tanto, la mayoría ordinaria. Como en la mayoría simple exige que se emitan más votos a favor que en contra no hay necesidad de mencionar que la mayoría lo es de voto válidamente emitidos, sólo se computan a favor o en contra votos válidos, los nulos no cuentan ni en un sentido ni en otro. Tampoco es preciso realizar aclaraciones sobre los votos en blanco y a las abstenciones. Basta con comparar los votos emitidos a favor de la propuesta con los votos contrarios a ella.
}

15- Sobre la votación separada por asuntos, Díaz Moreno (2015a, p. 115125), Sánchez Calero (2015, p. 272) y Serrano Sánchez (2015, pp. 7595), Martín Molina (2014, p. 1-11) y Cabanas Trejo (2014, p. 8) al respecto, abordan que la reforma a la LSC incorporó el artículo 197 bis que en la junta general deberán votarse separadamente aquellos asuntos que sean sustancialmente independientes. En todo caso, aunque figuren en el mismo punto del orden del día, deberán votarse de forma separada: a) el nombramiento, la ratificación, la reelección o la separación de cada administrador; b) en la modificación de estatutos sociales, la de cada artículo o grupo de artículos que tengan autonomía propia; c) aquellos asuntos en los que así se disponga en los estatutos de la sociedad. Desde el punto de vista normativo el precepto constituye una novedad en el Derecho societario, no tiene antecedentes en las leyes anteriores, aunque no es un requisito que en primera convocatoria se obtenga la mayoría absoluta, es decir, más votos a favor que los sumen en contra y abstenciones, siempre que los accionistas presentes y representados concurrentes a la junta, posean al menos el $50 \%$ del capital suscrito con derecho a voto. En segunda convocatoria se requiere la concurrencia del 25\% o más del capital suscrito con derecho a voto, será necesario el voto favorable de $2 / 3$ del capital social presente o representado en la junta, pero si concurre más del $50 \%$ se aplicará la regla de la mayoría absoluta (artículo 201.2 LSC ${ }^{16}$ ). Los estatutos pueden elevar las mayorías indicadas (artículo 201.3 LSC ${ }^{17}$ ).

Para el caso de Nicaragua el artículo 262 CC, tratándose de los asuntos mencionados, la ley se refiere a una mayoría absoluta que requiere de las tres cuarte del capital presente para formar el quórum y la votación del cincuenta por ciento del capital presente o representado por lo menos. En otras palabras la mayoría absoluta para la votación se computarán con base a las acciones con derecho a voto, independientemente que para el quórum se haya considerado las acciones sin votos, las acciones cuyos socios se encuentran en mora, las acciones de socios que posiblemente se encuentren en situación de conflicto y las acciones de autocartera, todas las anteriores entran para el cómputo de asistencia y quórum, y solamente votarán los accionistas con derecho de hacerlo, debiendo llegar al cincuenta por ciento del capital presente 0 representado.

\section{Acuerdo unánime de celebrar una junta general universal}

tema desconocido, dicha regla se aplicaba al nombramiento o ratificación de consejero y en el caso de modificación de estatutos. Con la entrada en vigencia de la Ley 31/2014 de España, la idea a la que responde ha pasado a integrar el contenido de un mandato legal, que será de aplicación tanto para las sociedades cotizadas como a las no cotizadas. La votación separada se concretó en dos materias en las que la práctica societaria, no es infrecuente como es el nombramiento, la reelección o la separación de administradores y la modificación estatutaria. Este precepto trata de salvaguardar la autenticidad de la voluntad de la junta general, impidiendo que mediante el sencillo expediente de acumular en una sola votación diversos asuntos resulte tergiversada (oculta).

16-El apartado 2 del artículo 201 prevé dos mayorías que por ser superior a la ordinaria, se califica como reforzada (absoluta y dos tercios). Estas mayorías son para adoptar los acuerdos contenidos en el artículo 194 LSC. La ley reconoce mayoría reforzadas específicas en casos concretos, como en el caso de las sociedades cotizadas. La mayoría absoluta si el capital presente supera el $50 \%$ debe entenderse que el supuesto de hecho se dará cuando el capital concurrente supere la mitad del capital social suscrito con derecho al voto. Por el contrario se requerirá el voto favorable de dos tercios del capital presente o representado en la junta cuando en segunda convocatoria concurran accionistas que representen el $25 \%$ del capital suscrito con derecho a voto (Díaz Moreno, 2015b, p. 148; Serrano Sánchez, 2015, pp. 75-95 y Muñoz de Dios (1985, p. 877).

17- La libertad estatutaria para regular las mayorías necesarias para adoptar acuerdos en junta general encuentran otros límites adicionales. El primero se encuentran en los apartados 1 y 2 del artículo 201 pueden ser modificado por sentido: alza, no pueden rebajarse o disminuirse Díaz Moreno (2015b, p. 149). 
La junta universal no se encuentra regulado de manera expresa, la única forma que se presente en la práctica nicaragüense es pactando esta modalidad de junta, fundándose en el principio de libertad de contratación del artículo $2437 \mathrm{C}$ y el artículo 203 CC de Nicaragua, que permite señalar otras modalidades posibles y legales como es el caso que nos ocupa.

Para Otero Lastres (2007, p. 1229-1244), Uría (1993, p. 320), Muñoz Planas (1994, pp. 1046-1056) y Vicent Chuliá (1991, p. 613) no es suficiente que todos los accionistas se reúnan físicamente, sino que es necesario acordar la celebración de la junta general de accionista, por unanimidad para que la junta universal sea válida (STS de España: 31-5-1999). La doctrina ha opinado que la exigencia de unanimidad y no de mayoría se debe a que sea una causa la posible indefensión de los socios que se verán obligados a votar acuerdos no conocidos de antemano, sin estar previamente informados.

Esta desinformación del socio, debería impedir que se tomaran acuerdos sobre asuntos de especial importancia, como por ejemplo en el caso de fusión o modificación estatutaria. En ese sentido, la STS de España: 29-12-1999, que bastaría la discrepancia de cualquier socio, aunque no alcanzara el mínimo estatutario para asistir y deliberar, para no poder celebrar la junta.

Consideramos que la falta de información previa a la junta universal es uno de los problemas que se manifiestan y pone en duda la validez de los acuerdos emitidos, por dicha limitación y la ausencia de los requisitos de convocatoria, entre otras situaciones. En Nicaragua, además de los defectos señalados en este tipo de junta, deberá pactarse en el contrato social y estatutos la validez de este tipo de juntas. Será suficiente, señalar que habrá junta general de accionistas siempre que se encuentre reunido el $100 \%$ del capital social y unánimemente decida celebrar una junta general.

Según Sánchez Linde (2007a, pp. 32-33) la celebración de junta universal de accionistas en la sociedad anónima, implica la existencia de dos factores, que deben darse conjuntamente:

a) Que todo el capital social suscrito de la sociedad esté presente de manera efectiva, a través de su dueño o poseedor;

b) Ninguno de ellos se oponga a que se celebre la junta de accionistas en ese momento.

Comprendemos que al señalar todo el capital suscrito, debe entenderse el capital pagado y no pagado de la sociedad. Este criterio es fundamental dejarlo claro porque en los estatutos no podrá señalarse que solamente deben estar las acciones con derecho al voto, pues en ese caso, no tendría validez el acuerdo emitido por la junta. Por otra parte, será válido que se persone el representante, pero solamente en el caso que éste ostente un mandato generalísimo, pues no lo consideramos válido cuando lo hace con un poder especial, el cual debe ser más preciso, incluso en qué dirección manifestará la voluntad del accionista al momento de votar.

Manifiesta Rodríguez Artigas (2009, p. 1-18) que la exigencia de la unanimidad obedece a que es una decisión que deben adoptar los socios porque la junta universal aún no ha nacido como órgano colegiado, por esa razón se ofrece un modo decisorio, que es la unanimidad, menos dificultoso que con relación a su operatividad que el principio mayoritario. La unanimidad, funciona de modo automático y comprobable por todos, pero se malogra en cuanto algún participante expresa en la colectividad su no comunión con los demás asuntos a aprobar.

En el contexto nicaragüense la junta universal no tiene fundamento legal que lo reconozca, excepto la libertad de contratación referida. Sin embargo considerando lo dispuesto en el epígrafe XVII del Título Preliminar del Código Civil de Nicaragua [Publicado en la Gaceta Diario Oficial No. 2148 de 5 de febrero de 1904, (en los sucesivo, C de Nicaragua)] reconoce que cuando nos encontremos ante una cuestión que no puede resolverse ni por las palabras ni por el espíritu de la ley, se atenderá a los principios de leyes análogas; y si aún la cuestión fuere dudosa, se resolverá por los principios generales del Derecho.

Para Muñoz-Planas (1994, p. 1046), Uría (1993, p. 320; 1976a, p. 649), Lucas Fernández (1991, p. 338), y Girón Tena (1952, p. 311) la exigencia de un acuerdo unánime para celebrar la junta, sea una mera cuestión de procedimiento o de funcionamiento, la aceptación unánime de la condición universal, de una junta en ciernes, supone el automático y total desistimiento, por parte de todos los asistentes, de una futura impugnación de los acuerdos adoptados en cuanto a motivos fundados en defecto de convocatoria. En ese mismo, orden de ideas, dentro del análisis de la decisión unánime colectiva adoptada por los socios, que exige la ley (artículo 178 LSC de la España), debe remarcarse que el acuerdo unánime de los accionistas no solamente se refiere a la intención de convertir esa reunión espontánea en una auténtica junta, sino que conlleva la decisión por unanimidad de los puntos del orden del día (Sánchez Calero, 1997, pp. 12-15). En ese sentido destaca el contenido del artículo 97 del Reglamento de Registro Mercantil de España, en sus apartados 3 y 4 en el que se exige que en el acta de junta universal conste a continuación de la fecha y lugar de celebración, el orden del día de la junta, junto con el nombre de los asistentes, seguido de las firmas de cada uno de ellos.

Por nuestra parte, somos de la opinión que es aceptable por parte de los accionistas, la decisión unánime de celebrar la junta universal siempre que conste en el contrato social y los 
estatutos (artículo 124 y 203 CC de Nicaragua). Tiene sentido, asimismo, aprobar el orden del día, porque de qué les sirve aprobar la celebración de la junta, sin que se consideren los temas a desarrollar para ser deliberado. Este criterio, permite que los accionistas pueda ejercer el derecho de información que será dado por quienes tienen la obligación de hacerlo en ese momento.

En la práctica, la mayoría de juntas universales celebradas conllevan la existencia previa de una convocatoria informal, la cual incluye un orden del día provisional u oficioso, esta práctica no implica que dicho orden del día no deba aprobarse de manera unánime por los asistentes; también puede darse el caso de que alguno de los presentes haya asistido desconociendo el orden del día provisional u oficioso, lo cual implicará una indefensión del socio asistente no conocedor de aquel (Broseta Pont y Martínez Sanz (2011, p. 419).

Es común en la práctica nicaragüense, establecer este tipo de convocatoria informal. Generalmente si los socios conocen para qué fueron convocados y en particular, cuando se trate de asuntos relevantes de la sociedad que requiere ser decidido de manera inmediata. Por lo tanto, consideramos válido incluir esta información previa a los accionistas, para ejecutar en tiempo el Derecho de información. Sin embargo, no podemos decir, que al aceptar la junta universal en el contrato social, los socios renuncian a los requisitos de información, pues este derecho se considera irrenunciable.

En relación con los sujetos que han de participar en la decisión o sumarse participar en la unanimidad, el actual artículo 178 LSC de España dispone que la junta general quedará válidamente constituida para tratar cualquier asunto, sin necesidad de previa convocatoria, siempre que esté presente 0 representada la totalidad del capital social y los concurrentes acepten por unanimidad la celebración de la reunión. Implica que deberá participar en el acuerdo la totalidad de los socios o, mejor dicho, que deberán participar todos aquellos sujetos cuyos títulos computen como capital social y estén presentes en la reunión o sus representantes. Es decir, todo aquel que aporte capital, pero la cuestión de qué títulos han de tenerse en cuenta para el cómputo del capital social, es una situación discutida en la doctrina.

Se deduce que en el sistema español al igual que en el Derecho societario nicaragüense se acepta considerar que constituida la junta universal se incluya en el cómputo las acciones sin voto y de las pertenecientes a acciones morosas. La cual no nos parece ilógica, pues se requiere la totalidad del capital social.

También se incluyen a los titulares de acciones rescatables, pero no a los titulares de obligaciones canjeables o convertibles en acciones, ya que éstos no representan capital ni tampoco los obligacionistas. No es incluyente en la una- nimidad otros sujetos que no son socios pero que ejercen funciones administrativas en la sociedad, como el gerente u otro funcionario que tenga vinculación directa con la gestión social, tal como los tenedores de bonos u obligacionistas o cualquier otro sujeto que pueda estar presente en la junta en virtud de autorización estatutaria. Sin embargo, sí habrían de estar presentes y sumarse a la unanimidad los acreedores pignoraticios o los usufructuarios de acciones, cuando tengan asignado el ejercicio de los derechos del accionista, pues, ellos representan en ese acto el capital social asociados a los títulos de los cuales en ese momento son poseedores y no propietarios.

En lo que se refiere a las acciones propias, de acuerdo a lo regulado en el artículo 233 CC de Nicaragua, no deben ser tomadas en cuenta a la hora del cómputo, considerando que la disposición citada no establece cómo administrar este tipo de acciones, pero la parte final de la norma deja clara su naturaleza, al señalar que serán amortizadas. Por su parte Girón Tena (1952, p. 311) señala que la doctrina mayoritaria no las considera para el cómputo de la totalidad del capital social en la junta universal, igual sucede con acciones de una sociedad que posea acciones de otra compañía que su vez participa en la suya, por un valor de $10 \%$ del capital social, en tanto no se haya procedido a la venta o reducción) o las adquiridas sobrepasando el $10 \%$ del capital social en otra sociedad sin notificación.

Rodríguez Artigas (1994, p. 451) considera válida la asistencia y la participación en la decisión unánime de los representantes de los socios ausentes, según lo regulado actualmente en el artículo 184 LSC. Por otra parte, Garrigues y Uría (1976, p. 650) están en contra de la posición anterior, opinan que tratándose de una junta espontánea e imprevista no es factible que nadie de los asistentes a la reunión haya sido dotado del oportuno poder especial de representación que la ley exige. Este poder debe tener las instrucciones en su caso, todo ello en concordancia para emitir el voto dentro del orden del día provisional u oficioso que consta en la convocatoria informal. Bajo estas dos posiciones, parece que la doctrina dominante admite la representación para conseguir la unanimidad, pero se encuentran dificultades, en cuanto el representante del socio se enfrenta con asuntos del orden del día inesperados, puesto que en la junta no existe convocatoria previa ni orden del día publicados, aunque es cierto que en la mayoría de las ocasiones existe un orden del día en el acto de la reunión espontánea, dentro de los debates previos entre los asistentes.

Consideramos válido el poder otorgado al representante, siempre que éste cuente con las facultades determinadas en dicho mandato, por ello, consideramos más viable que un mandato generalísimo o general que uno especial, porque en este caso requiere mayores requisitos para poder ejercer el derecho en la junta universal. Pero sucede que en la práctica 
se remite una notificación a los socios sobre los asuntos a tratar y en ese caso, el socio que no puede asistir podrá otorgar un poder especial.

Rodríguez Artigas (1966, p. 452) refiriéndose a la representación familiar en junta universal, señalan que si nos encontramos en este supuesto, ésta tiene un especial tratamiento, porque no se exige ni siquiera un poder de representación (artículo 187 LSC) y debe entenderse que el mismo ha de unirse siempre a la búsqueda de la unanimidad para la celebración de la junta, aunque siempre le queda al representante el remedio de votar en contra del asunto debatido, cuando considere que su aprobación puede perjudicar a su mandante. Igual actitud se espera del representante, cuando éste ostente poder general conferido en documento público con facultades para administrar todo el patrimonio del representado.

Contrario al señalamiento de Rodríguez Artigas, en Nicaragua se requiere el otorgamiento de poder a los familiares (artículo 3293 C y siguientes de Nicaragua), pues no existe esa representación automática para ejercer los derechos consignados en el acta constitutiva, que solamente la tienen los accionistas, los cuales pueden transferir entre vivos o por causa de muerte a través de una secesión testada o intestada. En caso contrario, no puede un familiar actuar en esa calidad.

En otro orden de ideas, debe estudiarse en el supuesto de la participación en la decisión unánime de los socios que puedan participar a distancia o de forma extra asamblearia. Al respecto en la Ley 26/2007 de España, relativa a la transparencia de sociedades anónimas, se permite votar en la junta también al socio que no se encuentra físicamente y en ella se incorporó un nuevo apartado al artículo 105 numeral 4 de la LSA, ahora contenido en 189 numeral 2 y 3 de LSC de España. En ese sentido, un socio podrá emitir su voto para la decisión unánime de celebrar la junta de accionista, para que una vez constituida, puede votar los diferentes puntos del orden del día, también extra asambleariamente, lo puede hacer a través de email u otro medio telemático, puede inclusive seguir el desarrollo de la junta a través de medios televisivos o informáticos (Otero Lastres, 2007, pp. 1229-1244; Sánchez Álvarez, 1999, p, 287-308; Uría, Menéndez y Muñoz Planas, 1992, p. 118).

Consideramos que es un tema discutible en el derecho nicaragüense, porque no existe regulación sobre la junta universal, sin embargo, si en los estatutos se dispone que la junta universal se celebre de manera virtual, entonces se estaría aceptando el mismo criterio que hemos venido señalando, lo importante es que exista un mecanismo que permita la identificación del sujeto accionista para declarar la validez de la junta, a través de la votación unánime para acordar la modalidad de junta y el orden de día.
En lo que concierne al momento de perfección del acuerdo unánime, es precisamente el momento de su constitución de la junta universal que la toma de decisión mediante un sistema de unanimidad se aproxima a una declaración de voluntad del órgano, conjunta y automática, incluso, presumida. Una vez aprobada por unanimidad, podemos encontrarnos con un abandono de un número determinado de socios, hecho que no afecta la validez de la misma.

El problema es que si la junta nace desde que acuerdan de forma unánime y el orden del día se decide en el transcurso de la junta, entonces queda vulnerable a ser aplicado el principio mayoritario contenido en el artículo 124.14 CC de Nicaragua. Es contradictorio que en una junta creada y nacida siga rigiendo para ciertas cuestiones la unanimidad, aunque ciertos asuntos se vayan decidiendo por mayoría. En ese sentido, conviene entonces decidir unánimemente y antes de la junta, tanto la constitución como el orden del día de la misma, y una vez realizada estas dos operaciones debe considerarse que la junta ha nacido. Si en la reunión el accionista abandona la reunión, entonces no se podría incluir nuevos puntos del orden del día por la falta de capital por ser considerado junta universal.

\section{Conclusiones}

El principio de mayoría es el que predomina en la junta general de accionistas de la sociedad anónima nicaragüense, dicho principio se aplica tanto cuando se aprueba un acuerdo como en el caso contrario de desaprobación y que según el artículo 124.14 CC de Nicaragua obliga a todos los socios. Este criterio se materializa en los artículos 254 y 262 CC incluyendo a los accionistas que no hayan participado en la junta caracterizando el acuerdo como obligatorio, excepto el ejercicio de la acción de impugnación de acuerdo a lo preceptuado en el artículo 261 CC de Nicaragua.

El principio de mayoría presupone la existencia de una uniformidad de intereses comunes de los accionistas que declaran su voluntad frente al orden del día, aprobando o desaprobando, aunque no siempre dichas declaraciones serán emitidas en un mismo sentido, pero el acuerdo debe contar con los votos necesarios.

En el sistema nicaragüense no caben las deliberaciones y acuerdos sobre asuntos fuera de su competencia, en todo caso serán objeto de impugnación según a lo regulado en el artículo 261 CC de Nicaragua, siendo considerados como nulos e inexistentes por sentencia judicial.

El cómputo de las acciones no parte de todo el capital de la sociedad, sino sobre las acciones presente o representadas en la junta, sin embargo los estatutos deberán regular la forma de deliberar y de tomar los acuerdos, siendo generalmente la mitad más uno, es decir, más de la mitad de los 
votos computables. La mayoría puede ser reforzada con una votación especial según lo regulado en el artículo 262 CC de Nicaragua. Asimismo, los estatutos podrán regular dicha situación, pero sin exigir una mayoría que supere el quórum de asistencia requerido y sin que se determine la unanimidad para la adopción de los acuerdos.

En el Derecho nicaragüense el cómputo de la mayoría se toman en cuenta los votos presentes, disidentes, incluyendo los votos en blanco, más no las acciones propias, obligando la mayoría a la minoría, excepto que se opongan a los acuerdos y ejerciten la acción de protesta. Por otra parte, los accionistas que tienen suspenso sus derechos de voto no serán tomados en cuenta.

El sistema que siguen los artículos 254 y 262 CC de Nicaragua es el de mayoría absoluta, por ello se debe partir del artículo $253 \mathrm{CC}$ referidos al quórum de asistentes presentes con derecho a voto para concluir que existe una vinculación directa que nos aleja a otro tipo de interpretación respecto a la mayoría simple.

Es aceptable y válido los pactos entre socios en los cuales limiten su libertad de voto y obligarse con otros socios a votar en otro sentido, dichos acuerdos parasociales permanecen en el recinto de las relaciones de quienes lo suscriben.

En el contrato social y estatutos se reglamentará el modo y la forma para hacerlo afectivo, pues el párrafo segundo del artículo 254 permite pactar estatutariamente y determinar el número de votos que pueden ser efectivamente emitidos por los accionistas presentes y calcular sobre la base de la mayoría legal o estatutaria.

No cabe regular la unanimidad para adoptar los acuerdos, siendo objeto de nulidad la cláusula que la contenga tal exigencia, por cuanto el artículo 124.14 del CC es imperativo y requiere que se pacte en las condiciones que establece, excepto lo regulado en la parte final del artículo 244 CC de Nicaragua que dispone un caso especial de decisión unánime cuando la reelección de los administradores no esté prevista en el contrato social y estatutos, la cual contradice el artículo 254 CC de Nicaragua sobre el principio de proporcionalidad, por lo que deberá ser regulado expresamente para evitar confusión.

Cuando se someten a deliberación los puntos del orden del día previamente aprobado por unanimidad por los accionistas en junta universal las decisiones se tomarán por mayoría de capital de acuerdo a lo preceptuado en el artículo 254 y 262 CC de Nicaragua y lo que se pacte en los estatutos.

\section{Referencias bibliográficas}

- Boldó Roda, C (2013). Lección 8a. Derecho y deberes del socio. En Grimaldos García, M. I (Dir). Derecho de sociedades. Para los estudios de grado. (141-152). Murcia: Diego Marín.

- Boquera Matarredona, J (2008). La Junta General de las Sociedades Capitalistas. Madrid: Thomson-Aranzadi.

- Broseta Pont, M y Martínez Sanz, F (2011). Manual de derecho mercantil. $18^{\mathrm{a}}$ edición. Volumen I. Madrid. Tecnos

- Cabanas Trejo, R (2014). Cambios en el régimen de la junta general de las sociedades de capital en la reforma del gobierno corporativo (Ley 31/2014, de 3 de diciembre). Diario La Ley, № 8442, Sección Doctrina, 16 de Diciembre de 2014, Año XXXV, Ref. D-421. Madrid: Editorial LA LEY

- Calaza López, M (2003). El proceso de formación de voluntad social de las sociedades anónimas y cooperativas. Madrid: Dykinson

- Casado de Pablos, Y (2002). Adopción de acuerdos en la junta general de accionistas por mayoría. Localización: BFD: Boletín de la Facultad de Derecho de la UNED, N² 20, 2002, págs. 365-392. Recuperado el 13 de junio de 2015, en http://dialnet.unirioja.es/servlet/ articulo?codigo $=1039387$

- $\quad$ Cruz Rivero, D, (2013). La junta general. En Jiménez Sánchez, G. J y Díaz Moreno, A (Dir). Derecho mercantil. Las sociedades mercantiles. Volumen $3.0 .15^{\mathrm{a}}$ edición actualizada. (pp. 471-512). $2^{\mathrm{a}}$ edición: Marcial Pons.

- De la Cámara Álvarez, M (1979). Carácter temporal del cargo de administrador de las sociedades anónimas. Comentario a la sentencia del T. S. de 10 de junio de 1978. RDM. (pp. 275-300). Número 152

- Díaz Moreno, A, (2015a). Artículo 197 bis. Votación separa por asuntos, en comentario de la reforma del régimen de las sociedades de capital en materia de gobierno corporativo (Ley 31/2014). En Juste Mencía, J (Coord). Sociedades no cotizadas. (pp. 115-125). Navarra: Civitas

- Díaz Moreno, A, (2015b). Artículo 201. Mayorías, en comentario de la reforma del régimen de las sociedades de capital en materia de gobierno corporativo (Ley 31/2014). En Juste Mencía, J (Coord). Sociedades no cotizadas. (pp. 132-152). Navarra: Civitas 
- Díaz-Pintado, M (1994). Junta General de Accionistas. Artículo 103.2 párrafo $2 .^{\circ}$ Comentario sobre la mayoría de votación de dos tercios del Capital presente o representado exigida en segunda convocatoria, cuando la asistencia no supere el cincuenta por ciento del capital suscrito con derecho a voto. Diario La Ley, 1994. (pág. 1101). Tomo 2. Editorial LA LEY 12457/2001

- Esteban Velasco, G (1998). Algunos aspectos relevantes de la regulación de la junta general de los socios en la nueva ley de Sociedades de responsabilidad limitada de 1995. In Estudios de Derecho mercantil: homenaje al profesor Justino F. Duque (pp. 233-258). Universidad de Valladolid.

- Fernández de la Gándara, L (2010). Derecho de sociedades. T. II .Valencia: Tiran lo Blanch

- Fernández del Pozo, L. (1992). La transparencia de los sindicatos de voto entre accionistas. Su publicidad. (pp. 83-128). Revista de Derecho Bancario y Bursatil, (45).

- Fernando de la Gándara, L (2007). Estudios de derecho de sociedades y derecho concursal. Libro homenaje al profesor Rafael García Villaverde. Tomo I.(pp. 532-562). Madrid: Marcial Pons.

- García de Enterría, J (2002). La limitación estatutaria del número máximo de votos de una accionista. Operativdad y aplicación práctica. Diario La Ley, No 5473 , Sección Doctrina, 1 de Febrero de 2002, Año XXIII, Ref. D-34 (p. 1703 y ss) Tomo 2, Editorial LA LEY

- Garrigues, J y Uría, R (1976). Comentarios a la ley de sociedades anónimas, 3era edición, Tomo I. Madrid.

- Girón Tena, J (1952). Derecho de sociedades anónima. Valladolid. Marcial Pons

- Hernando Cebriá, L (2011). El conflicto entre socios en situaciones de igualdad en las sociedades de capital. Cuadernos de derecho y comercio. Núm. 56, Diciembre 2011. Pp. 87-133 Recuperado el 27 de junio de 2015, en http://app.vlex.com/\#WW/search/content type:4+jurisdiction:ES/el+voto+dirimente+de+presidente+ de+junta+general/WW/vid/379522102

- Iglesias, J. L y García de Enterría, J (2012). Las sociedades de capital. En Menéndez, A y Rojo, A (Dir). Lecciones de Derecho mercantil. Pamplona: Vol. I. 12 edición. Civitas.

- Lucas Fernández, F (1991). Temas sobre sociedades anónimas. Escrituras de constitución ampliación de capi- tal Madrid. Editorial Revista de Derecho Privado. Madrid: Edersa

- Madina, F. (2004). La adopción de acuerdos en la sociedad anónima: quorum de constitución y mayorías. Marcial Pons.

- Martín Molina, P (2014). Las reforma del gobierno corporativo. Diario La Ley, Nº 8493, Sección Tribuna, 4 de Marzo de 2015, Ref. D-85, Editorial LA LEY 1538/2015

- Mesa Tejeda, N. T (2010). Reflexiones en torno a la adopción de acuerdos sociales. En la Sociedad Anónima Cubana: Especial Referencia A Las Empresas Mixtas. Revista e-mercatoria, (2), (pp. 111-125). Recuperado el 2 de septiembre, en http://dialnet.unirioja.es/servlet/ articulo?codigo $=3579838$

- Muñoz de Dios, G (1985). Capital suscrito o desembolsado para ejercicio del voto en la sociedad anónima. 1985, pág. 877, tomo 3, Editorial LA LEY 5799/2001

- Muñoz Planas (1994) Junta universal y acciones sin voto. Revista jurídica española de doctrina, jurisprudencia y bibliografía, ISSN 0211-2744, №2. (pp. 1046-1051). La Ley

- Olivencia Ruiz, M (2005). Algunas cuestiones sobre el derecho de voto en la sociedad anónima (la crisis del principio de mayoría). Escritos jurídicos. Volumen II. (pp. 95-114).Sevilla. Fundación El Monte.

- Otero Lastres, J. M (2007). El requisito de la aceptación unánime en la junta universal de la sociedad anónima, en Libro Homenaje al Profesor Sánchez Calero, Vol. II., (pp. 1229-1244). Madrid. Marcial Pons.

- Paz-Ares, C (2003). El enforcement de los pactos parasociales. Actualidad jurídica Uría y Menéndez, (5).pp. 19-42

- Peña Nossa, L (2011). De las sociedades comerciales. Colombia, Bogotá Universidad Santo Tomás. Sexta edición. Editorial Temis.

- Pérez Moriones, A (1997). Los sindicatos de voto para la Junta General de la Sociedad Anónima. Valencia

- Polo Sánchez, E (1973). Reflexiones sobre el régimen de quórum y de mayoría en los órganos colegiados de la S.A; (pp. 201 y ss). RDM, abril-septiembre.

- Recalde Castells, A. J (1996). Limitación estatutaria del derecho de voto en las sociedades de capitales. Madrid: Civitas 
- Rodríguez Artigas (1994). La Junta general de socios, en la reforma del derecho de sociedades de responsabilidad limitada, Rds, número extraordinario, Pamplona

- Rodríguez Artigas, F (1966). Derecho de minoría, en Derecho de sociedades de responsabilidad limitada. Madrid. McGraw-Hill.

- Rodríguez Artigas, F. (1995). La Junta General de socios. AA. VV., Derecho de sociedades de responsabilidad limitada. En Rodríguez Artigas, F., García Villaverde, R., Fernández de la Gándara, L., Alonso Ureba, A., Velasco San Pedro, L. y Esteban Velasco, G, 1(coord). Mc Graw Hill, Madrid.

- Rodríguez Artigas, F. (2009). La junta general en la encrucijada. Jornada Internacional "Reflexiones sobre la Junta General de las sociedades de capital", organizada en el marco del proyecto de investigación SEJ 200763752/JURI "Estudio de la función de la Junta General en las sociedades de capital: problemas y propuestas de solución". Recuperado el 14 de agosto de 2015, en http://eprints.ucm.es/9224/1/Rodr\%C3\%ADguez_ARtigas._UCM.pdf

- Ruiz Rojas, R (2014). Asamblea de socios o accionistas en las sociedades mercantiles: Validez de las Asambleas. Recuperado el 12 de agosto de 2014, en http://vlex. com/ $\mathrm{vid} / 490320922$

- Sánchez Álvarez, M. (1999) Junta universal, remoción del administrador y representación del socio, RdS, núm. 13 (Comentario de la sentencia del 23 de septiembre de 1997).

- Sánchez Calero, F (2015). Principios de Derecho mercantil. Revisado por Sánchez-Calero Guilarte. $20^{\mathrm{a}}$ ed. Pamplona: Aranzadi

- Sánchez Calero, F (2015). Principios de Derecho mercantil. Revisado por Sanchez-Calero Guilarte. 20ª ed. Pamplona: Aranzadi

- Sánchez Calero, F y Sánchez-Calero Guilarte (2013). Instituciones de Derecho Mercantil. 36 edición. Navarra. Aranzadi

- Sánchez Linde, M (2007a). El acuerdo unánime de celebrar junta universal en la sociedad anónima. Aspectos materiales y formales, p(pp.32 y 33). Revista de Derecho Bancario y Bursátil, $n^{0} 105$

- Sánchez Linde, M (2007b). El acuerdo unánime de celebrar Junta universal en la sociedad anónima. Aspectos materiales y formales. Revista de Derecho Bancario núm. 105/2007. BIB 2013/38889. Lex Nova, Valladolid. Recuperado el 28 de agosto de 2014, en http://aranzadi.aranzadidigital.es/maf/app/document?docguid=Idf1ade4021a 411e3805b010000000000\&srguid=i0ad8181600000148 862fb38459a6fcb7\&src=withinResuts\&spos=1\&epos $=1 \&$ displayid=\&publicacion=\&clasificationMagazines=\&fecha comun=\&numeropub-tiponum=

- Sánchez Línde, M (2009a). El principio de mayoría en la adopción de acuerdos de junta general de sociedades anónimas. Revista de Derecho de Sociedades. Número 33. Rds. Monografía. Navarra. Aranzadi

- Sánchez Linde, M (2010). El acuerdo social en la sociedad anónima. Reflexiones en torno a su naturaleza jurídica. Actualidad Civil, № 12, Sección A Fondo, Quincena del 16 al 30 Jun. 2010, tomo 1, LA LEY 4432/2010. Editorial LA LEY. p. 1351

- Sánchez Línde, M, (2009b). La posible atribución de voto de calidad o voto dirimente al presidente de la junta de accionistas de la sociedad anónima. En Rodríguez Artigas, F, Farrando Miguel, I, González Castilla, F y Tena Aguirre, $\mathrm{R}$ (Dir). Cuestiones actuales. Academia matritense del notariado. (pp. 357-365). Colegio de notarios de Madrid.

- Sánchez-Calero Guilarte, J (2010). La igualdad de trato de los accionistas ¿un principio general?. En Rodríguez Artigas, F, Fernández de la Gándara, L, Quijano Gónzalez, J, Alonso Ureba, A, Velasco San pedro, L, Esteban Velasco, G (Dir). Revista de Derecho de Sociedades. Año, 2010-2, Número 35. (pp. 19-32). Pamplona. Aranzadi

- Serrano Sánchez, M, (2015). Derecho de sociedades y de crisis empresarial. En Prades Cutillas, D (Coord). Tratados y manuales. $2^{\mathrm{a}}$ edición. (pp. 75-154). Navarra: Thomson Reuters.

- Uría, Menéndez, Muñoz Planas (1992). La junta general de accionistas. En comentarios al Régimen de las sociedades mercantiles. Civitas.

- Uría, R (1993). Derecho mercantil. Vigésima edición. Madrid. Marcial Pons

- Uría, R, Menéndez, A y García de Enterría (1999). La sociedad anónima: órganos sociales. La junta general de accionistas. En Uría, R y Menéndez, A. Curso de Derecho Mercantil. Tomo I, Madrid. Civitas.

- Vicent Chuliá, F (1991).Compendio crítico de Derecho mercantil. 3era edición Barcelona, Bosch 